\title{
ANALISIS FRAMING BERITA KASUS AHOK DALAM POLEMIK SURAT AL-MAIDAH 51 PADA KOMPAS.COM DAN REPUBLIKA.CO.ID
}

Didik Hariyanto, Finalni Pritituesdina

Fakultas Ilmu Sosial dan Ilmu Politik Jurusan Ilmu Komunikasi, Universitas Muhammadiyah Sidoarjo

Email: didikhariyanto@umsida.ac.id finalnigitu@gmail.com

\begin{abstract}
This study aims to determine the construction of the media on Ahok's preaching in the polemic on Al-Maidah 51 (analysis of framing on kompas.com and republika.co.id edition 27 September - 27 December 2016). The research method used is a qualitative research method framing analysis of Zhongdang Pan and Gerald M. Kosicki models. The results of the framing analysis of Ahok in Polemik Surat Al-Maidah 51 that, news articles published by the two online news portals are not neutral. Kompas.com, looks very strongly in defense of Ahok, while Republika.co.id looks very strongly in defense of Muslims. Group affiliation and interest sentiment are very influential in this news. This can be seen from the analysis using the agenda theory setting which greatly affects the Kompas.com and Republika.co.id online media in the selection of news.
\end{abstract}

Keywords: Framing analysis, media construction, agenda setting, Al-Maidah-51

\begin{abstract}
Abstrak
Penelitian ini bertujuan untuk mengetahui dan menganalisis konstruksi media terhadap pemberitaan Ahok dalam polemik Surat Al-Maidah 51 (analisis framing pada kompas.com dan republika.co.id edisi 27 Septemebr - 27 Desember 2016). Penelitian ini menggunakan metode kualitatif dengan analisis framing model Zhongdang Pan dan Gerald M. Kosicki. Hasil analisis framing terhadap Ahok dalam Polemik Surat AlMaidah 51 bahwa, artikel berita yang dimuat oleh ke dua portal berita on line tidak netral. Kompas.com, terlihat sekali sangat membela Ahok, sedangkan Republika.co.id terlihat sekali sangat membela umat Islam. Afiliasi kelompok dan sentimen kepentingan sangat berpengaruh dalam pemberitaan ini. Agenda setting sangat mempengaruhi media online Kompas.com dan Republika.co.id dalam pemilihan berita.
\end{abstract}

Kata Kunci: Analisis framing, konstruksi media, agenda setting, Surat Al-Maidah 51

\section{PENDAHULUAN}

Media online saat ini menjadi salah satu saluran yang banyak dipilih oleh khalayak dalam mendapatkan informasi yang dibutuhkannya. Media online mempunyai kelebihan dalam kecepatan sajian berita dibandingkan dengan media massa yang lain. Berita media online dapat langsung diakses oleh penggunanya dari smartpon dimanapun mereka berada 
dengan catatan masih terjangkau oleh jaringan internet. Seperti halnya, media massa media online juga memiliki fungsi penghantar dalam menyebarkan berbagai macam pengetahuan, menyelenggarakan kegiatan dalam lingkungan publik yang dapat dijangkau segenap anggota masyarakat secara bebas, sukarela, umum, dan murah, hubungan antara pengirim dan penerima seimbang dan sama, serta mampu menjangkau lebih banhyak orang daripada institusi lainnya. (McQuail, 1987: 51)

Pemberitaan pada media massa dapat dipengaruhi oleh kepemilikan media. Menurut Ngatmin (2015:02), bahwa kompas merupakan surat kabar yang didirikan oleh P.K.Ojong. Pendiri kompas ini merupakan penganut agama Katolik dan merupakan pengurus Ikatan Sarjana Katolik Indonesia, sedangkan Republika adalah media yang didirikan oleh kaum komunitas muslim. Kehadiran Ikatan Cendekiawan Muslin Indonesia menetapkan tiga program utama yang salah satunya adalah mendirikan penerbitan yang diberi nama Republika. Melalui Yayasan Abdi Bangsa yang dibentuk pada tanggal 17 Agustus 1992, ICMI secara resmi mendirikan penerbitan Republika.
Dalam ekonomi politik media, kepemilikan media juga berpengaruh pada penyajian berita. Begitu juga terhadap media online, yang tidak akan pernah lepas dari afiliasi kelompok atau latarbelakang pemiliknya. Media online bukan hanya sekedar medium lalu lintas pesan, antara unsur-unsur sosial dalam suatu masyarakat, melainkan juga sebagai alat penundukan dan pemaksaan konsensus oleh kelompok yang dominan secara ekonomi dan politik. Melalui pola kepemilikan dan melalui produk-produk yang disajikan, media adalah perangkat ideologi yang melanggengkan dominasi kelas pemodal terhadap publik. Media online juga dapat merepresentasikan diri sebagai ruang publik yang utama dan turut menentukan dinamika sosial, politik, dan budaya ditingkap lokal maupun global (Sudibyo, 2004: 1).

Kasus Ahok dalam polemik Surat AlMaidah 51 yang sedang hangat pemberitaannya, dikonstruksi oleh kedua media online ini melalui sudut pandang yang berbeda. Seperti pada kompas.com, berita dugaan penistaan agama ini dimuat hampir setiap hari oleh kompas.com. Headline atau judul berita terkesan membela dan mengunggulkan Ahok sebagai pihak yang tidak bersalah. Seperti headline berita yang dimuat pada, 28 
September 2016 "Ahok dilaporkan ke Bawaslu karena mengutib ayat Al Quran. Sama halnya pada republika.co.id, berita dugaan penistaan agama yang dilakukan Ahok, juga hampir setiap hari dimuat. Headline pada setiap berita terkesan membela umat Islam dan menjatuhkan Ahok, seperti headline berita yang dimuat pada 28 September 2016 "Majelis Ulama Indonesia mendesak Polri untuk menangkap Ahok karena dianggap melecehkan Al-Quran”. Berdasarkan permasalahan tersebut, maka tujuan yang diharapkan dari penelitian ini adalah untuk mengetahui bagaimana media mengkonstruksi pemberitaan Ahok dalam polemik Surat Al-Maidah 51 (analisis framing pada kompas.com dan republika.co.id edisi 27 September - 27 Desember 2016).

\section{Landasan Teoretis}

Teori Agenda Setting

Teori Agenda Setting adalah teori yang menyatakan bahwa media massa mempunyai kemampuan untuk mentransfer dua faktor yaitu kesadaran dan informasi ke dalam agenda publik yang mengarah pada kesadaran publik serta perhatiannya kepada isu-isu yang dianggap penting oleh media massa. (Tamburaka, 2012: 23). Menurut Mc Coms dan Donald Shaw penonton tidak hanya mempelajari berita dan informasi lainnya melalui media massa, tetapi juga mempelajari seberapa besar tekanan yang dilakukan oleh media massa terhadap suatu isu atau topik tertentu (Effendi, 2000 :288).

\section{Konstruksi Media}

Konstruksi media adalah keadaan ketika sebuah peristiwa yang sama diberitakan secara berbeda oleh media. Wartawan akan mempunyai perspektif yang berbeda ketika melihat suatu peristiwa dan itu dapat dilihat dari berbagai konstruksi peristiwa yang diwujudkan dalam teks berita (Eriyanto, 2012: 20). Hall dalam Tamburaka (2012: 85) mengatakan bahwa eksistensi media massa saat ini bukan mereproduksi realitas atau sebagai penyalur informasi tetapi justru menentukan realitas atau melakukan pembingkaian melalui pemakaian katakata tertentu yang dipilih. Jika ada berita yang menampilkan kerusuhan sosial misalnya, hal ini bukanlah sekedar realitas yang sebenarnya, melainkan lebih merupakan pantulan keikutsertaan media massa tersebut dalam mengkonstruksi realitas. Dalam ungkapan lain, fakta yang dilaporkan oleh jurnalis kepada pembaca sebenarnya bukanlah fakta yang sesungguhnya. Jurnalis melalui strategi pembingkaiannya telah mengkonstruksi 
fakta yang dilihatnya melalui kategori dan ideologinya.

\section{Framing}

Menurut Pan dan Kosicki (1993, 5575), mendefinisikan framing adalah proses membuat suatu pesan lebih menonjol, menempatkan informasi lebih dari pada yang lain sehingga khalayak lebih tertuju pada pesan tersebut. Perangkat ini dapat diinterpretasikan ke dalam empat struktur besar: sintaksis, skrip, tematik, dan retoris.

a). Sintaksis, merupakan cara wartawan dalam menyusun opini, peristiwa, pernyatan, kutipan, pengamatan peristiwa kedalam susunan umum berita. Pada struktur sintaksis, analisis difokuskan pada skema berita, meliputi judul, lead, latar informasi, kutipan sumber, pernyataan, dan penutup

b). Skrip, merupakan cara wartawan dalam mengisahkan atau menceritakan peristiwa kedalam bentuk berita. Struktur ini melihat bagaimana strategi cara bercerita atau tutur yang dipakai wartawan dalam mengemas peristiwa ke dalam berita. Pada struktur skrip, analisis difokuskan pada kelengkapan berita meliputi 5W+1H (what, where, when, who, why, dan how).

c). Tematik, merupakan cara wartawan mengungkapkan pandangannya atas sebuah peristiwa ke dalam proposisi dan kalimat dalam membentuk teks secara keseluruhan. Pada struktur skrip, analisis difokuskan pada paragraf proposisi, kalimat, hubungan antarkalimat

d). Retoris, merupakan cara bagaimana wartawan menentukan arti ke dalam berita. Pada struktur skrip, analisis difokuskan pada kata, idiom, gambar/foto, grafik (Eriyanto, 2012: 295).

\section{Metode Penelitian}

Studi ini menggunakan pendekatan analisis framing yaitu cara untuk menonjolkan pesan, memberikan porsi pada informasi tertentu lebih dari pada yang lain sehingga khalayak lebih tertuju pada pesan tersebut. Perangkat ini dapat diinterpretasikan ke empat struktur besar yaitu sintaksis, skrip, tematik, dan retoris. Sumber data studi dari data primer dan data sekunder. Data primer diperoleh dari berita kasus penistaan agama oleh Ahok yang di muat di kompas.com dan republika.co.id edisi 28 September, 20 Oktober, 5 November, 2 Desember, 5 Desember, dan 13 Desember. Data Sekunder dalam penelitian ini adalah Buku-buku yang berkaitan dengan teori agenda setting, analisis framing, dan konstruksi media.

\section{Hasil dan Pembahasan}

Dari penganalisisan data, peneliti memberikan penjabaran 12 artikel yang 
terdiri 6 dari media kompas.com dan 6 dari media republika.co.id. Berikut hasil analisis dari kedua medoa tersebut:

1). Analisis framing model Pan dan Kosicki terhadap pemberitaan Ahok dalam polemik Surat Al-Maidah 51 pada Kompas.com

\section{a). Struktur Sintaksis}

Kompas.com hanya menggunakan satu ide saja. Ini terlihat pada berita edisi 28 September 2016, 10 Oktober 2016, dan 5 Desember 2016. Terdapat artikel yang seluruhnya berisikan sudut pandang dari penulis, yaitu pada edisi 5 November 2016 dan 2 Desember 2016. Pemilihan kutipan sumber adalah orang-orang yang pro terhadap Ahok. Seperti pada edisi 5 Desember yang berjudul "Hendardi: penetapan tersangka kepada Ahok karena tekanan massa". Hendardi merupakan ketua dari Lembaga Swadaya Masyarakat (LSM) Setara Institute aktif. LSM ini fokus pada penegakkan Hak Asasi Manusia (HAM), keberagaman, solidaritas dan menjunjung tinggi martabat manusia. Hendardi merupakan pemeluk agam Kristen, sehingga terlihat sekali dalam artikel bahwa Hendardi membela Ahok. Pemilihan sudut pandang penulis pada lead dan penutup artikel, menggambarkan pembelaan terhadap Ahok. Sirra Prayuna,
Ketua Tim Advokasi Calon Gubernur DKI Jakarta Basuki Tajahaja Purnama.

b). Struktur Skrip

Kompas.com menonjolkan unsur who, what, when, where, how yang lengkap. Tetapi, pada edisi 5 November 2016 tidak terdapat unsur why pada artikel. Artikel yang berjudul menata "emosi usai aksi damai 4 November 2016" tidak menjelaskan mengapa kericuhan terjadi, padahal sebelumnya aksi damai berjalan sangat tertib. Hal tersebut merupakan kecacatan bagi sebuah berita.

c). Struktur Tematik

Beragam tema yang hendak dimunculkan dalam artikel adalah penjelasan koherensi, sebagai penegas yang detail. Koherensi-koherensi tersebut pertama-tama disampaikan oleh kompas.com melalui cara menulis fakta. Pada edisi 5 November dan 2 Desember 2016, seluruh artikel berisikan opini wartawan, tidak terdapat sumber data yang akurat pada artikel. Selanjutnya dalam beberapa artikel penegasan bahwa kompas.com membela Ahok terlihat pada artikel edisi 28 September, 10 November, 5 Desember, dan 13 Desember 2016. Dimana paragraf dalam artikel menggambarkan sosok Ahok sebagai orang yang berani, tulus, pemimpin yang 
tidak anti terhadap islam, pemimpin yang terbuka, dan pemimpin yang adil.

d). Struktur Retoris

Selain elemen leksikon dan gaya bahasa penekanan fakta ditunjukkan pada gambar yang dipilih untuk melengkapi artikel. Pada kompas.com banyak kata ganti yang memiliki banyak makna seperti pada edisi 5 November 2016 terdapat kata provokasi, memperkeruh suasana, pihakpihak tertentu, para pendompleng, mulut para oportunis, jari-jari para netizen, mulut besar, kicauan, bombastis, dan intervensi. Pemiliahan kata tersebut digunakan untuk mewakili opini dari penulis dan mengaburkan tujuan dilakukannya aksi damai 4 November 2016. Gambar yang dipilih untuk melengkapi artikel terkesan mengunggulkan Ahok dan memaksakan pembaca untuk membela Ahok.

2). Analisis framing model Pan dan Kosicki terhadap pemberitaan Ahok pada polemik Surat Al-Maidah 51 pada Republika.co.id

\section{a). Struktur Sintaksis}

Dilihat dari struktur sintaksis pada Republika.co.id hanya menggunakan satu ide. Kutipan sumber berasal dari tokohtokoh Islam yang kontra terhadap Ahok. Tokoh-tokoh islam tersebut antara lain, Mahmudi, Ketua MUI Kota Serang, Ahmad Syafii Maarif mantan Ketua
Pimpinan Pusat (PP) Muhammadiyah), Abdullah Gymnastiar (AA Gym) yang merupakan seorang pendakwah, penulis buku, dan pendiri Pondok Pesantren Daarut Tauhid di Bandung, Ustaz Felix Xiauw adalah seorang pendakwah muda dan penulis buku-buku islam keturunan Tionghoa yang menjadi muaalaf. Sebelumnya Ustaz Felix Xiauw merupakan penganut agama kristen katolik. Muhammad Mahendradatta yang merupakan Ketua Dewan Pembina Tim Pengacara Muslim (TPM). Pada keseluruhan artikel tidak ditemukan opini penulis, seluruhnya berasal dari pernyataan sumber yang didapat melalui wawancara.

\section{b). Struktur Skrip}

Struktur skrip pada republika.co.id, juga menonjolkan unsur who, what, when, where, how yang lengkap. Tetapi pada edisi 13 Desember 2016 tidak terdapat unsur how pada artikel. Artikel yang berjudul "jaksa dinilai professional di sidang Ahok" tidak menjelaskan bagaimana dakwaan yang merupakan unsur utama yang diungkapkan oleh Jaksa Penuntut Umum (JPU) unuk menahan Ahok. Hal tersebut merupakan kecacatan berita. 
c). Struktur Tematik

Pada republika.co.id koherensi pertama-tama disampaikan melalui paragraf-paragraf yang berisikan ungkapan tokoh-tokoh Islam yang kontra terhadap Ahok. Sangat jelas terlihat bahwa republika.co.id membela umat islam. Selanjutnya isi dalam artikel yang memojokkan Ahok terlihat pada edisi 28 September Mahmudi Ketua Umum MUI Kota Serang mengatakan bahwa Polri harus segera tangkap Ahok karena menurutnya pernyataan Ahok terhadap Surat Al-Maidah 51 sebagai penistaan dan pelecehan terhadap Agama Islam. Selain itu Mahmud juga mengungkapkan bahwa Ahok haram menginjakkan kakinya di wilayah hukum Kota Serang. Edisi 5 Desember, Ustaz Felix Xiau mengungkapkan kemarahannya kepada penista agama dan mengajak seluruh pemuda-pemuda muslimah untuk membela Al-Quran dan mengawal kasus tersebut dari awal sampai akhir. Kurangnya objektivitas terlihat jelas pada artikel edisi 5 November 2016 dimana fakta tidak dimunculkan dalam artikel. Seharusnya aksi damai berakhir ricuh namun yang dituliskan adalah aksi damai dari awal sampai akhir berjalan tertib. Hal ini dimaksudkan untuk menutup nutupi kejadian yang sebenarnya. d). Struktur Retoris

Pada republika.co.id tidak banyak kata ganti yang digunakan. Namun dalam satu artikel edisi 10 Oktober 2016 yang berisikan ungkapan permintaan maaf Ahok dikutipkan "saya bukan ahli Islam". Pernyataan tersebut semakin memperlihatkan bahwa Ahok mengutip Surat Al-Maidah 51 hanya sesuai dengan pengetahuannya saja. Mengingat Ahok bukanlah umat Islam sehingga Ia tidak mengetahui makna dibalik Surat AlMaidah 51. Hal ini semakin memperjelas bahwa Ahok memang benar melakukan penistaan terhadap Agama Islam dan memperjelas bahwa republika.co.id membela umat Islam dan menjatuhkan Ahok.

3). Perbandingan analisis framing pemberitaan Ahok dalam polemik Surat Al-Maidah 51 pada kompas.com dan republika.co.id

Media online kompas.com dan republika.co.id memiliki sudut pandang yang berbeda dalam menyajikan pemberitaan tentang kasus Ahok dalam polemik Surat Al-Maidah 51. Berikut peneliti sajikan perbandingan analisis data framing antara media Kompas.com dan media republika.co.id: 


\begin{tabular}{|c|c|c|}
\hline $\begin{array}{l}\text { Ele- } \\
\text { men }\end{array}$ & $\begin{array}{c}\text { Kompas } \\
\text {.com }\end{array}$ & $\begin{array}{c}\text { Republika } \\
\text {.co.id }\end{array}$ \\
\hline Frame & $\begin{array}{l}\text { Dilaporkan ke } \\
\text { Bawaslu } \\
\text { karena } \\
\text { mengutib ayat } \\
\text { dari kitab suci, } \\
\text { ini merupakan } \\
\text { tanggapan } \\
\text { Ahok }\end{array}$ & $\begin{array}{l}\text { MUI } \\
\text { mendesak } \\
\text { Polri untuk } \\
\text { menangkap } \\
\text { Ahok karena } \\
\text { telah } \\
\text { melecehkan } \\
\text { Al-Quran }\end{array}$ \\
\hline $\begin{array}{l}\text { Sintak } \\
- \\
\text { sis }\end{array}$ & $\begin{array}{l}\text { Wawancara } \\
\text { Ahok, } \\
\text { menurutnya } \\
\text { semua orang } \\
\text { boleh } \\
\text { mengutib } \\
\text { kitab suci, } \\
\text { karena kitab } \\
\text { suci terbuka } \\
\text { untuk umum. }\end{array}$ & $\begin{array}{l}\text { Wawancara } \\
\text { dengan Ketua } \\
\text { Umum MUI } \\
\text { Kota Serang, } \\
\text { Bahwa Ahok } \\
\text { telah } \\
\text { melakukan } \\
\text { pelecehan dan } \\
\text { penistaan } \\
\text { agama Islam }\end{array}$ \\
\hline Skrip & $\begin{array}{l}\text { Mengandung } \\
\text { unsur } 5 \mathrm{~W}+1 \\
\mathrm{H} \quad \text { yang } \\
\text { lengkap }\end{array}$ & $\begin{array}{l}\text { Mengandung } \\
\text { unsur } 5 \mathrm{~W}+1 \\
\mathrm{H} \quad \text { yang } \\
\text { lengkap }\end{array}$ \\
\hline $\begin{array}{l}\text { Tema } \\
\text {-tik }\end{array}$ & $\begin{array}{l}\text { Hanya } \\
\text { memperlihatk } \\
\text { an satu ide } \\
\text { saja, yaitu } \\
\text { pernyatan dari } \\
\text { Ahok yang } \\
\text { membantah } \\
\text { telah }\end{array}$ & $\begin{array}{l}\text { Hanya } \\
\text { memperlihatk } \\
\text { an satu ide } \\
\text { saja, yaitu } \\
\text { pernyataan } \\
\text { dari Ketua } \\
\text { Umum MUI } \\
\text { Kota Serang }\end{array}$ \\
\hline
\end{tabular}

\begin{tabular}{|l|l|l|}
\hline & $\begin{array}{l}\text { melakukan } \\
\text { pelecehan } \\
\text { terhadap Al- } \\
\text { Quran }\end{array}$ & \\
\hline $\begin{array}{l}\text { Reto- } \\
\text { ris }\end{array}$ & $\begin{array}{l}\text { Setiap baris } \\
\text { berisikan } \\
\text { pembelaan } \\
\text { terhadap } \\
\text { Ahok }\end{array}$ & $\begin{array}{l}\text { Setiap baris } \\
\text { berisikan } \\
\text { pembelaan } \\
\text { terhadap umat } \\
\text { islam }\end{array}$ \\
\hline
\end{tabular}

Tabel 1. Perbandingan Framing Edisi 28

September 2016

Sumber: Analisis Penulis

Pada artikel yang pertama ini didapatkan perbedaan pada struktur sintaksis, dimana kompas.com memilih Ahok sebagai sumber berita sedangkan republika memilih tokoh islam sebagai sumber berita.

\begin{tabular}{|c|c|c|}
\hline $\begin{array}{l}\text { Ele- } \\
\text { men }\end{array}$ & $\begin{array}{c}\text { Kompas } \\
\text {.com }\end{array}$ & $\begin{array}{l}\text { Republika } \\
\text {.co.id }\end{array}$ \\
\hline Frame & $\begin{array}{l}\text { Kepada umat } \\
\text { Islam Ahok } \\
\text { minta maaf }\end{array}$ & $\begin{array}{l}\text { Ahok Minta } \\
\text { maaf, agar } \\
\text { kasus Al- } \\
\text { Maidah } 51 \\
\text { tidak } \\
\text { dilanjutkan }\end{array}$ \\
\hline $\begin{array}{l}\text { Sintak- } \\
\text { sis }\end{array}$ & $\begin{array}{l}\text { Berisikan } \\
\text { pernyataan } \\
\text { Ahok, yang } \\
\text { meminta maaf } \\
\text { kepada umat } \\
\text { islam }\end{array}$ & $\begin{array}{l}\text { Hampir } \\
\text { seluruh } \\
\text { artikel berisi } \\
\text { kutipan } \\
\text { pernyataan } \\
\text { Ahok, namun }\end{array}$ \\
\hline
\end{tabular}




\begin{tabular}{|c|c|c|}
\hline & & $\begin{array}{l}\text { pada lead } \\
\text { tertulis judul } \\
\text { video, yang } \\
\text { tidak } \\
\text { dijelaskan } \\
\text { sumbernya }\end{array}$ \\
\hline Skrip & $\begin{array}{l}\text { Mengandung } \\
\text { unsur } 5 \mathrm{~W}+1 \\
\mathrm{H} \quad \text { yang } \\
\text { lengkap }\end{array}$ & $\begin{array}{l}\text { Mengandung } \\
\text { unsur } 5 \mathrm{~W}+1 \\
\mathrm{H \quad \text {yang }} \\
\text { lengkap }\end{array}$ \\
\hline $\begin{array}{l}\text { Tema- } \\
\text { tik }\end{array}$ & $\begin{array}{l}\text { Penggambaran } \\
\text { tentang sosok } \\
\text { Ahok yang } \\
\text { tidak } \\
\text { membenci } \\
\text { agama apapun } \\
\text { termasuk } \\
\text { islam }\end{array}$ & $\begin{array}{l}\text { Paragraf } \\
\text { dalam artikel } \\
\text { berisikan } \\
\text { pernyataan } \\
\text { permohonan } \\
\text { maaf Ahok } \\
\text { kepada umat } \\
\text { islam }\end{array}$ \\
\hline $\begin{array}{l}\text { Reto- } \\
\text { ris }\end{array}$ & $\begin{array}{l}\text { Menggunakan } \\
\text { banyak kata- } \\
\text { kata istilah dan } \\
\text { gambar yang } \\
\text { ditampilkan } \\
\text { dalam artikel } \\
\text { tidak } \\
\text { relevan } \\
\text { dengan isi } \\
\text { artikel }\end{array}$ & $\begin{array}{l}\text { Terdapat } \\
\text { kata "saya } \\
\text { bukan ahli } \\
\text { islam", kata } \\
\text { tersebut } \\
\text { diucapkan } \\
\text { oleh Ahok. } \\
\text { Kata tersebut } \\
\text { menjadi } \\
\text { Janggal } \\
\text { ketika } \\
\text { terucap dari } \\
\text { orang yang } \\
\text { bukan }\end{array}$ \\
\hline
\end{tabular}

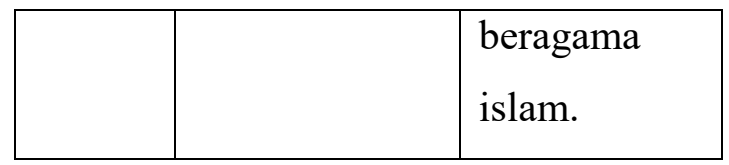

Tabel 2. Perbandingan Framing Edisi 10

Oktober 2016

Sumber: Analisis Penulis

Pada artikel yang kedua ini menampilkan tema berita yang sama, namun isi beritanya sangatlah berbeda. Hal tersebut terlihat dari perbedaan ketiga struktur yaitu sintaksis, tematik, dan retoris.

\begin{tabular}{|c|c|c|}
\hline $\begin{array}{c}\text { Eleme } \\
\mathbf{n}\end{array}$ & $\begin{array}{c}\text { Kompas } \\
\text {.com }\end{array}$ & $\begin{array}{c}\text { Republika } \\
\text {.co.id }\end{array}$ \\
\hline Frame & $\begin{array}{lr}\text { Menata } & \text { emosi } \\
\text { usai aksi } & \\
\text { damai } & 4 \\
\text { November } \\
2016\end{array}$ & $\begin{array}{l}\text { Buya Syafii } \\
\text { apresiasi } \\
\text { aksi } \\
\text { November }\end{array}$ \\
\hline $\begin{array}{l}\text { Sintak- } \\
\text { sis }\end{array}$ & $\begin{array}{l}\text { Penggambara } \\
\text { n suasana aksi } \\
\text { damai } \\
\text { November. } \\
\text { Pada akhir } \\
\text { artikel } \\
\text { dituliskan } \\
\text { bahwa proses } \\
\text { hukum } \\
\text { terhadap Ahok } \\
\text { yang telah } \\
\text { dijanjikan, } \\
\text { akan tetap } \\
\text { berlang-sung. }\end{array}$ & $\begin{array}{l}\text { Wawancara } \\
\text { dengan } \\
\text { tokoh besar } \\
\text { agama } \\
\text { Islam. } \\
\text { Dalam } \\
\text { artikel tidak } \\
\text { dituliskan } \\
\text { fakta } \\
\text { sebenarnya } \\
\text { tentang aksi } \\
4 \text { November. } \\
\text { Hanya } \\
\text { dituliskan }\end{array}$ \\
\hline
\end{tabular}




\begin{tabular}{|c|c|c|}
\hline & $\begin{array}{l}\text { Sehingga, } \\
\text { tidak perlu ada } \\
\text { intervensi dari } \\
\text { public }\end{array}$ & $\begin{array}{l}\text { bahwa aksi } \\
\text { demo } \\
\text { berjalan } \\
\text { tertib }\end{array}$ \\
\hline Skrip & $\begin{array}{l}\text { Tidak terdapat } \\
\text { unsur Why } \\
\text { dalam artikel }\end{array}$ & $\begin{array}{l}\text { Mengandun } \\
\text { g unsur } 5 \mathrm{~W} \\
+1 \mathrm{H} \text { yang } \\
\text { lengkap }\end{array}$ \\
\hline $\begin{array}{l}\text { Tema- } \\
\text { tik }\end{array}$ & $\begin{array}{l}\text { Seluruh artikel } \\
\text { berisikan } \\
\text { sudut pandang } \\
\text { penulis }\end{array}$ & $\begin{array}{l}\text { Paragraf } \\
\text { dalam artikel } \\
\text { merupakan } \\
\text { hasil } \\
\text { wawancara } \\
\text { dengan Buya } \\
\text { Syafii }\end{array}$ \\
\hline Retoris & $\begin{array}{l}\text { Banyak } \\
\text { menggunakan } \\
\text { kata istilah } \\
\text { yang } \\
\text { mengarah } \\
\text { pada } \\
\text { pembelaan } \\
\text { terhadap Ahok }\end{array}$ & $\begin{array}{l}\text { Tokoh yang } \\
\text { dipilih } \\
\text { adalah tokoh } \\
\text { islam. } \\
\text { Sehingga } \\
\text { terlihat } \\
\text { sekali artikel } \\
\text { mengarah } \\
\text { pada } \\
\text { pembelaan } \\
\text { terhadap } \\
\text { umat islam }\end{array}$ \\
\hline
\end{tabular}

Tabel 3. Perbandingan Framing Edisi 5 November 2016

Sumber: Analisis Penulis

Pada artikel yang ketiga ini menampilkan tema berita yang sama, namun isi beritanya sangatlah berbeda. Hal tersebut terlihat dari perbedaan keempat struktur.

\begin{tabular}{|c|c|c|}
\hline Elemen & $\begin{array}{l}\text { Kompas } \\
\text {.com }\end{array}$ & $\begin{array}{l}\text { Republika } \\
\text {.co.id }\end{array}$ \\
\hline Frame & $\begin{array}{l}\text { Sejumlah } \\
\text { massa } \\
\text { berteriak agar } \\
\text { Ahok } \\
\text { ditangkap } \\
\text { saat } \\
\text { rombongan } \\
\text { Jokowi lewat. }\end{array}$ & $\begin{array}{l}\text { Memberita- } \\
\text { kan tentang } \\
\text { Tausyiah Aa } \\
\text { Gym pada } \\
\text { aksi } 2 \\
\text { Desember }\end{array}$ \\
\hline $\begin{array}{l}\text { Sintak- } \\
\text { sis }\end{array}$ & $\begin{array}{l}\text { Artikel } \\
\text { berisikan } \\
\text { opini penulis }\end{array}$ & $\begin{array}{l}\text { Artikel } \\
\text { berisikan } \\
\text { Tausyiah Aa } \\
\text { Gym yang } \\
\text { disampaikan } \\
\text { kepada umat } \\
\text { islam dari } \\
\text { Bandung }\end{array}$ \\
\hline Skrip & $\begin{array}{l}\text { Mengandung } \\
\text { unsur } 5 \mathrm{~W}+1 \mathrm{H} \\
\text { yang lengkap }\end{array}$ & $\begin{array}{l}\text { Mengan- } \\
\text { dung unsur } \\
5 \mathrm{~W}+1 \mathrm{H} \\
\text { yang } \\
\text { lengkap }\end{array}$ \\
\hline Tematik & $\begin{array}{l}\text { Tidak } \\
\text { seimbang. } \\
\text { Karena } \\
\text { paragraf demi } \\
\text { paragraf } \\
\text { artikel ini }\end{array}$ & $\begin{array}{l}\text { Hanya ada } \\
\text { satu ide yaitu } \\
\text { isi Tausyiah } \\
\text { Aa Gym }\end{array}$ \\
\hline
\end{tabular}




\begin{tabular}{|l|l|l|}
\hline & $\begin{array}{l}\text { hanya } \\
\text { memunculkan } \\
\text { opini atau } \\
\text { sudut } \\
\text { pandang } \\
\text { penulis }\end{array}$ & \\
\hline Retoris & $\begin{array}{l}\text { Gambar yang } \\
\text { ditampilkan } \\
\text { memilik } \\
\text { kesesuaian } \\
\text { dengan isi } \\
\text { artikel }\end{array}$ & $\begin{array}{l}\text { Gambar } \\
\text { yang } \\
\text { ditampilkan } \\
\text { kemiliki } \\
\text { dengan isi } \\
\text { artikel }\end{array}$ \\
\hline
\end{tabular}

Tabel 4. Perbandingan Framing Edisi 2

Desember 2016

Sumber: Analisis Penulis

Pada artikel yang keempat ini menampilkan tema berita yang sama, namun isi beritanya sangatlah berbeda. Hal tersebut terlihat dari perbedaan keempat struktur.

\begin{tabular}{|c|c|c|}
\hline $\begin{array}{l}\text { Eleme } \\
\text { n }\end{array}$ & $\begin{array}{l}\text { Kompas } \\
\text {.com }\end{array}$ & $\begin{array}{l}\text { Republika } \\
\text {.co.id }\end{array}$ \\
\hline Frame & $\begin{array}{l}\text { Hendardi: } \\
\text { penetapan } \\
\text { tersangka } \\
\text { kepada } \\
\text { Ahok karena } \\
\text { adanya } \\
\text { tekanan } \\
\text { massa }\end{array}$ & $\begin{array}{l}\text { Ustaz Felix } \\
\text { Xiauw: Bela } \\
\text { Al-Quran } \\
\text { hingga tuntas }\end{array}$ \\
\hline
\end{tabular}

\begin{tabular}{|c|c|c|}
\hline $\begin{array}{l}\text { Sintak- } \\
\text { sis }\end{array}$ & $\begin{array}{l}\text { Wawancara } \\
\text { dengan } \\
\text { Hendardi } \\
\text { yang } \\
\text { menyatakan } \\
\text { bahwa kasus } \\
\text { Ahok } \\
\text { seharusnya } \\
\text { tidak } \\
\text { diteruskan } \\
\text { karena Ahok } \\
\text { telah } \\
\text { meminta } \\
\text { maaf ini } \\
\text { sesuai } \\
\text { dengan } \\
\text { PPRI No. } \\
\text { 1/PNPS } \\
\text { tahun 1965 }\end{array}$ & $\begin{array}{l}\text { Isi artikel } \\
\text { merupakan } \\
\text { kutipan dari } \\
\text { tweetan Ustaz } \\
\text { Felix Xiauw di } \\
\text { akum media } \\
\text { sosialnya }\end{array}$ \\
\hline Skrip & $\begin{array}{l}\text { Mengandun } \\
\mathrm{g} \quad 5 \mathrm{~W}+1 \mathrm{H} \\
\text { yang } \\
\text { lengkap }\end{array}$ & $\begin{array}{l}\text { Mengandung } \\
5 \mathrm{~W}+1 \mathrm{H} \text { yang } \\
\text { lengkap }\end{array}$ \\
\hline $\begin{array}{l}\text { Tema- } \\
\text { tik }\end{array}$ & $\begin{array}{l}\text { Paragraf } \\
\text { yang } \\
\text { disampaikan } \\
\text { dalam } \\
\text { artikel } \\
\text { seluruhnya } \\
\text { adalah } \\
\text { pernyataan } \\
\text { dari }\end{array}$ & $\begin{array}{l}\text { Paragraf dalam } \\
\text { artikel } \\
\text { menggambarka } \\
\text { n kemarahan } \\
\text { Ustaz Felix } \\
\text { Xiauw kepada } \\
\text { orang yang } \\
\text { telah } \\
\text { menistakan }\end{array}$ \\
\hline
\end{tabular}




\begin{tabular}{|c|c|c|}
\hline & $\begin{array}{l}\text { Hendardi, } \\
\text { yang kata- } \\
\text { katanya } \\
\text { yang } \\
\text { dilontarkan } \\
\text { berpihak } \\
\text { terhadap } \\
\text { Ahok }\end{array}$ & $\begin{array}{l}\text { agama. Ustaz } \\
\text { Felix Xiauw } \\
\text { juga mengajak } \\
\text { seluruh umat } \\
\text { islam untuk } \\
\text { memperjuangk } \\
\text { an agar orang } \\
\text { yang } \\
\text { menistakan } \\
\text { agama segera } \\
\text { mendapatkan } \\
\text { hukuman }\end{array}$ \\
\hline $\begin{array}{l}\text { Reto- } \\
\text { ris }\end{array}$ & $\begin{array}{l}\text { Menggunak } \\
\text { an istilah } \\
\text { Due process } \\
\text { of law. } \\
\text { Menurut } \\
\text { Yusril Ihza } \\
\text { Mahendra } \\
\text { merupakan } \\
\text { proses } \\
\text { penegakkan } \\
\text { hukum yang } \\
\text { benar dan } \\
\text { adil, bukan } \\
\text { berdasarkan } \\
\text { kebencian }\end{array}$ & $\begin{array}{l}\text { Pembelaan } \\
\text { terhadap umat } \\
\text { islam sangat } \\
\text { mencolok } \\
\text { dalam artikel } \\
\text { ini. Hal } \\
\text { tersebut } \\
\text { diperkuat } \\
\text { dengan Frasa } \\
\text { “'takbiratul } \\
\text { ihram' dan } \\
\text { 'rakaat pertama' } \\
\text { tengah } \\
\text { berlangsung, } \\
\text { dan masih } \\
\text { panjang ibadah } \\
\text { sampai 'salam' } \\
\text { nanti”. Frasa } \\
\text { yang } \\
\text { digunakan }\end{array}$ \\
\hline
\end{tabular}

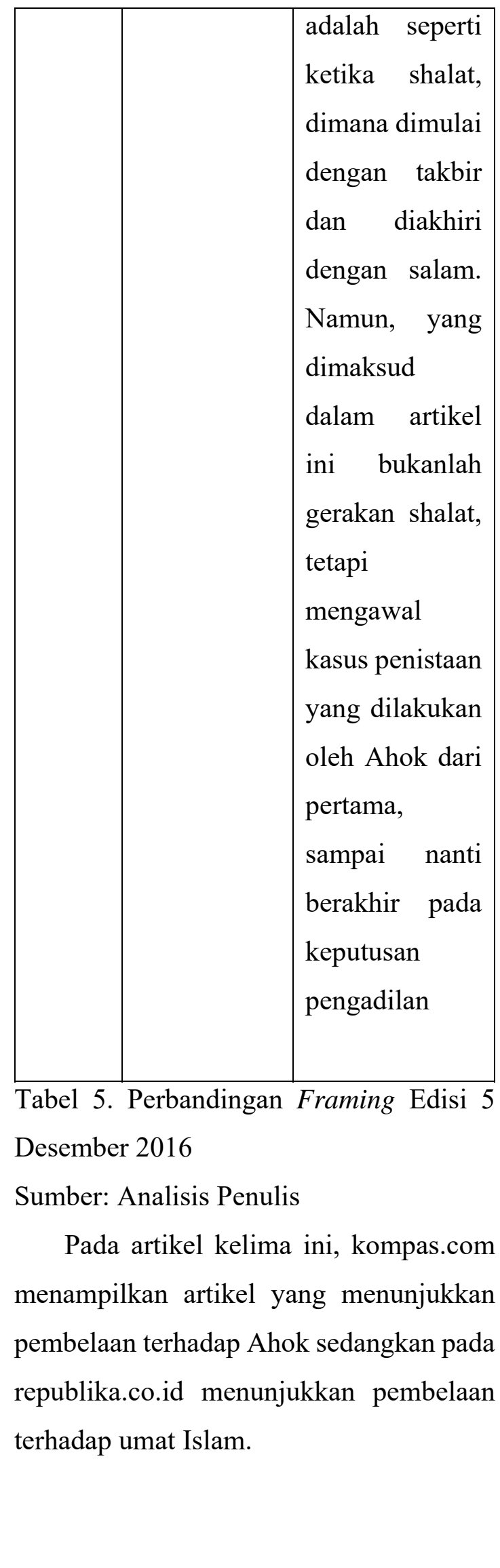




\begin{tabular}{|c|c|c|}
\hline $\begin{array}{l}\text { Ele- } \\
\text { men }\end{array}$ & $\begin{array}{l}\text { Kompas } \\
\text {.com }\end{array}$ & $\begin{array}{l}\text { Republika } \\
\text {.co.id }\end{array}$ \\
\hline Frame & $\begin{array}{l}\text { Berbagai } \\
\text { polemik } \\
\text { jelang sidang } \\
\text { perdana } \\
\text { Ahok }\end{array}$ & $\begin{array}{l}\text { Jaksa dinilai } \\
\text { Profesional di } \\
\text { Sidang } \\
\text { perdana Ahok }\end{array}$ \\
\hline $\begin{array}{l}\text { Sintak } \\
\text {-sis }\end{array}$ & $\begin{array}{l}\text { Artikel } \\
\text { menguraikan } \\
\text { tentang } \\
\text { permasalahan } \\
\text { yang muncul } \\
\text { menjelang } \\
\text { sidang } \\
\text { perdana } \\
\text { Ahok }\end{array}$ & $\begin{array}{l}\text { Artikel } \\
\text { menguraikan } \\
\text { tentang } \\
\text { jalannya } \\
\text { sidang yang } \\
\text { menurut Tim } \\
\text { Pengacara } \\
\text { Muslim } \\
\text { (TPM), Jaksa } \\
\text { Penuntut } \\
\text { Umum (JPU) } \\
\text { membacakan } \\
\text { dakwaan } \\
\text { dengan sangat } \\
\text { baik dan } \\
\text { seluruh } \\
\text { dakwaan } \\
\text { tersampaikan }\end{array}$ \\
\hline Skrip & $\begin{array}{l}\text { Mengandung } \\
\text { unsur } \\
5 \mathrm{~W}+1 \mathrm{H} \text { yang } \\
\text { lengkap }\end{array}$ & $\begin{array}{l}\text { Tidak terdapat } \\
\text { unsur How }\end{array}$ \\
\hline $\begin{array}{l}\text { Tema- } \\
\text { tik }\end{array}$ & $\begin{array}{l}\text { Penjelasan } \\
\text { satu persatu } \\
\text { apa saja yang }\end{array}$ & $\begin{array}{l}\text { Penggambara } \\
\text { n kemenangan }\end{array}$ \\
\hline
\end{tabular}

\begin{tabular}{|c|c|c|}
\hline & $\begin{array}{l}\text { menjadi } \\
\text { polemik, } \\
\text { khususnya } \\
\text { pada paragraf } \\
6\end{array}$ & $\begin{array}{l}\text { ada di tangan } \\
\text { umat islam }\end{array}$ \\
\hline $\begin{array}{l}\text { Reto- } \\
\text { ris }\end{array}$ & $\begin{array}{l}\text { Gambar tidak } \\
\text { berkesesuaia } \\
\mathrm{n} \quad \text { dengan } \\
\text { artikel }\end{array}$ & $\begin{array}{l}\text { Gambar yang } \\
\text { ditampilkan } \\
\text { sesuai dengan } \\
\text { artikel }\end{array}$ \\
\hline
\end{tabular}

Tabel 6. Perbandingan Framing Edisi 13

Desember 2016

Sumber: Analisis Penulis

Pada artikel yang kedua ini menampilkan tema berita yang sama, namun isi beritanya sangatlah berbeda. Hal tersebut terlihat dari perbedaan ketiga struktur yaitu sintaksis, tematik, dan retoris.

\section{Kesimpulan dan Saran}

Hasil penelitian ini terhadap polemik Surat Al-Maidah 51 yang dilakukan oleh Ahok pada media online kompas.com dan republika.co.id edisi 27 September-27 Desember 2016, dengan menggunakan analisis framing model Zhongdang Pan dan Gerald M. Kosicki, diperoleh kesimpulan sebagai berikut:

a). Media kompas.com dan republika.co.id, sangatlah berlawanan dalam mengkonstruksi berita kasus Ahok dalam polemik Surat Al-Maidah 51. Kompas.com menganggap kasus Ahok 
merupakan ketidaksengajaan dan tidak perlu di besar-besarkan. Sedangkan republika.co.id menganggap kasus Ahok sebagai kesengajaan dan harus segera ditindaklanjuti.

b). Dari hasil analisis framing dapat diketahui bahwa teori agenda setting sangat mempengaruhi media online kompas.com dan republika.co.id dalam pemilihan berita. Framing yang dilakukan kompas.com terhadap berita kasus penistaan agama oleh Ahok, sangat berpihak pada Ahok. Sementara framing yang dilakukan republika.co.id, sangat berpihak pada umat Islam. Kedua media online tersebut tidak menunjukkan objektivitas dan netralitas dalam pemberitaan-pemberitaanya, pada kasus penistaan agama oleh Ahok. Media yang seharusnya tidak mengaburkan realitas, mengedepankan objektivitas, dan netralitas.

Saran

Saran yang dapat diberikan peneliti setelah melakukan analisis framing pada pemberitaan kasus Ahok dalam polemik Surat Al-Maidah 51 yaitu media online kompas.com dan republika.co.id, diharapkan agar mengedepankan kebenaran informasi dibandingkan mengedepankan ideologi.

\section{Daftar Pustaka}

Asegaf, D. (1991). Jurnalistik media massa. Jakarta: Ghalia Indonesia.

Assegaf, D. (1983). Jurnalistik masa kini. Jakarta: Ghalia Indonesia.

Bungin, B. (2008). Sosiologi komunikasi: teori paradigma, dan diskusi teknologik komunikasi di masyarakat. Jakarta: Prena Media Group.

Effendi, A. (2000). Ilmu, teori, dan filsafat komunikasi. Bandung: Citra Aditya Bakti.

Eriyanto. (2012). Analisis framing (konstrukis media, ideologi, dan politik media. Yogyakarta: LKiS.

Eriyanto. (2012). Analisis wacana (pengantar analisis teks media). Yogyakarta: LKiS.

McQuail, D. (2000). Teori komunikasi massa, Jakarta: Salemba Humanika

Sobur, A. (2012). Analisis teks media. Bandung: ROSDA.

Stanley J Baran, D. K. (2010). Teori dasar komunikasi pergolakan dan masa depan massa. Jakarta: Salemba Humanika.

Sudibyo, A. (2004). Ekonomi politik media penyiaran. Yogyakarta: LKiS.

Tamburaka, A. (2012). Agenda setting media massa. Jakarta: Rajawali Pers.

Ngatmin, M. (2011). Analisis Framing Kasus Poligami K $H$ Abdullah 
Gymnastiar di Media kompas dan republika. Skripsi diterbitkan. Yogyakarta: Fakultas Dakwah UIN. https://www.google.co.id/amp/s/app.kom pas.com/amp/megapolitan/read/2016/ 09/28/11393361/dilaporkan.ke.bawas lu.karena.kutip.ayat.dari.kitab.suci.ini .tanggapan.ahok diakses tanggal 17 Juni 2017

https://www.google.co.id/amp/s/app.kom pas.com/amp/megapolitan/read/2016/ $\underline{10 / 10 / 09245441 / \text { ahok.minta.maaf.ke }}$ pada.umat.islam diakses tanggal 17 Juni 2017

https://www.google.co.id/amp/s/app.kom pas.com/amp/nasional/read/2016/11/ $\underline{05 / 08332041 / \text { menata.emosi.usai.aksi. }}$ damai.4.november.2016 diakses tanggal 17 Juni 2017

https://www.google.co.id/amp/s/app.kom pas.com/amp/nasional/read/2016/12/ $\underline{02 / 16550611 / \text { massa.doa.bersama.teri }}$ akkan.tangkap.ahok.saat.rombongan.j okowi.lewat diakses tanggal 17 Juni 2017

https://www.google.co.id/amp/s/app.kom pas.com/amp/megapolitan/read/2016/ 12/05/16421141/hendardi.penetapan.t ersangka.kepada.ahok.karena.tekanan .massa diakses tanggal 17 Juni 2017 https://www.google.co.id/amp/s/app.kom pas.com/amp/megapolitan/read/2016/ 12/13/06063511/berbagai.polemik.jel ang.sidang.perdana.ahok diakses tanggal 17 Juni 2017

https://www.google.co.id/amp/m.republik a.co.id/amp_version/oercfz282 diakses tanggal 17 Juni 2017 https://www.google.co.id/amp/m.republik a.co.id/amp_version/oeta9n361 diakses tanggal 17 Juni 2017 https://www.google.co.id/amp/m.republik a.co.id/amp_version/og4cv8361 diakses tanggal 17 Juni 2017

https://www.google.co.id/amp/m.republik a.co.id/amp version/ohje6o330 diakses tanggal 17 Juni 2017 https://www.google.co.id/amp/m.republik a.co.id/amp_version/ohqysc377 diakses tanggal 17 Juni 2017 https://www.google.co.id/amp/m.republik a.co.id/amp version/oi44an361 diakses tanggal 17 Juni 2017 